\title{
El principio de prohibición y la clausura del derecho internacional como sistema normativo: Hans Kelsen y la historia de un barco $^{12}$
}

The principle of probibition and the closing of international law as a regulatory system; Hans Kelsen and the bistory of a boat

\section{Natalia M. Luterstein \\ nluterstein@derecho.uba.ar}

Abogada (Universidad de Buenos Aires), LL.M. en Derecho Internacional Público (The London School of Economics and Political Science) y Doctoranda en Derecho Internacional Público (Universidad de Buenos Aires). Profesora de Derecho Internacional Público y Derecho Internacional Penal en la Universidad de Buenos Aires.

Resumen: El presente trabajo analiza el impacto del dictum de la Corte Permanente de Justicia Internacional en el caso "S.S. Lotus" en cuanto afirmó que "las restricciones a la independencia de los Estados no pueden ser presumidas", ya que "las reglas del derecho internacional deben emanar exclusivamente de su libre voluntad expresada en alguna de las fuentes creadoras de derecho" conforme la interpretación y el funcionamiento del ordenamiento jurídico internacional a la luz de la teoría de Han Kelsen y de las críticas realizadas por Carlos Alchourrón y Eugenio Bulygin sobre el alcance del principio de prohibición y la completitud de los sistemas normativos jurídicos.

Palabras claves: Derecho Internacional; Principio de prohibición; Hans Kelsen; Sistemas normativos; lagunas jurídicas.

\begin{abstract}
This papers examines the impact of the dictum of the Permanent Court of International Justice in the "S.S. Lotus" case when it stated that "restrictions upon the independence of States cannot be presumed" and that "the rules of law binding upon States therefore emanate from their own free will as expressed in conventions or by usages generally accepted as expressing principles of law" on the interpretation and the functioning of the international legal order in light of the theory of Hans Kelsen and the critics advanced by Carlos Alchourrón and Eugenio Bulygin regarding the principle of prohibition and completeness of the normative legal systems.
\end{abstract}

Key words: International Law; Prohibition principle; Hans Kelsen; Normative Systems; Legal Lacunae

1 Artículo enviado el 07.09.2016 y aceptado el 01.06.2017.

2 Asumiendo la plena responsabilidad por errores e imprecisiones, la autora desea agradecer la lectura y comentarios de Emiliano Buis, Eduardo Magoja y Nahuel Maisley.

Número de página no utilizable para citar 


\section{Introducción}

El 7 de septiembre de 1927 la Corte Permanente de Justicia Internacional emitió su sentencia en el caso "S.S. Lotus". Allí, afirmó que las restricciones a la independencia de los Estados no pueden ser presumidas, ya que las reglas del derecho internacional deben emanar exclusivamente de su libre voluntad expresada en alguna de las fuentes creadoras de derecho. Esta famosa frase ha sido interpretada como una manifestación del principio de prohibición, es decir, aquello que los Estados no han decidido prohibir por su propia voluntad, debe entenderse como permitido. Esta decisión de la Corte de principios del siglo XX continúa influenciando la forma en que se interpreta actualmente el derecho internacional, sin perjuicio de nuevas corrientes que consideran que la voluntad de los Estados ya no representa el único criterio de análisis.

El presente trabajo tiene como objetivo analizar el impacto del dictum de la Corte Permanente de Justicia Internacional en la interpretación y en el funcionamiento del ordenamiento jurídico internacional a la luz de la teoría de Han Kelsen y las críticas realizadas por Carlos Alchourrón y Eugenio Bulygin sobre el alcance del principio de prohibición y la completitud de los sistemas normativos jurídicos.

\section{La sentencia de la Corte Permanente de Justicia Internacional en el caso "S.S. Lotus"}

En agosto de 1926, el "Boz-Kourt" - un barco de bandera turca- colisionó con el "S.S. Lotus" -navío de pabellón francés- en alta mar, cerca de la costa de Turquía. El primer barco se partió en dos y ocho nacionales turcos perdieron la vida. Las autoridades turcas iniciaron un proceso penal contra el primer oficial del "S.S. Lotus", el Sr. Demons, de nacionalidad francesa y contra el capitán del "Boz-Kourt", de nacionalidad turca. Ambos fueron hallados culpables por un tribunal penal de Estambul y condenados a una pena de prisión de algunos meses y a pagar una multa. Esta decisión del gobierno turco de juzgar a un nacional francés fue el origen de una controversia internacional entre ambos Estados que decidieron de común acuerdo llevarla ante la Corte Permanente de Justicia Internacional (en adelante, “CPJI”) para que la resolviera. La Corte debía decidir, inter alia, si Turquía, al ejercer jurisdicción sobre un nacional francés, había violado principios de derecho internacional. 
El 7 de septiembre de ese año, la CPJI emitió su famosa sentencia en una decisión dividida, ${ }^{3}$ en la que el Presidente debió desempatar. Allí, afirmó que lo que el Tribunal debía resolver era si existía alguna norma que impedía a Turquía ejercer su jurisdicción ${ }^{4}$ y no, como sostenía Francia, si el Estado demandado había actuado sobre la base de algún criterio jurisdiccional reconocido por el derecho internacional. ${ }^{5}$

El planteo que la CPJI hizo del problema implicaba que no debía determinarse la existencia de una permisión, sino, por el contrario, la existencia de una prohibición y, en ese caso, si ella había sido violada por Turquía. ${ }^{6}$

La CPJI justificó esta postura haciendo referencia a la propia naturaleza del derecho internacional, considerando que se trata de un ordenamiento que regula las relaciones entre Estados independientes, cuyas reglas deben emanar exclusivamente de su libre voluntad expresada en alguna de las fuentes creadoras de derecho. En consecuencia, la CPJI sostuvo que las restricciones a la independencia de los Estados no pueden ser presumidas. ${ }^{7}$ En este sentido, el Tribunal afirmó que, si bien el derecho internacional prohíbe a los Estados ejercer su jurisdicción en el territorio de otro Estado sin un permiso, ello no equivale a sostener que también prohíbe el ejercicio de la jurisdicción en su propio territorio respecto de casos que tengan lugar fuera de éste porque no existe una regla general que lo prohíba. Por el contrario, la CPJI afirmó que el derecho internacional deja a discreción de los Estados qué principios jurisdiccionales adoptar. ${ }^{8}$

Asimismo, el Tribunal sostuvo que, aun si adoptara la posición francesa que sostenía que el carácter exclusivamente territorial de la jurisdicción implicaba que su ejercicio extraterritorial necesitaba un permiso expreso, de todas maneras, lo primero que se debía determinar es la existencia de dicha restricción (la de ejercer una jurisdicción extraterritorial). ${ }^{9}$ Así, la CPJI manifestó que si se afirmara que la práctica dispone que el derecho internacional no establece como exclusiva la jurisdicción de los Estados cuyo pabellón flameara en el barco, en casos de colisiones en alta mar, no sería necesario discernir si existe una restricción más general, ya que el hecho de que ya esté establecido que no existe una prohibición con respecto a una colisión el alta mar sería lo mismo que una regla permisiva especial. ${ }^{10}$

3 La mayoría de los votos disidentes se basaron en una comprensión diferente del alcance del principio de jurisdicción territorial, salvo Lord Finlay, quien disintió expresamente con la forma en que la CPJI había planteado el problema: en su opinión, no se trataba de probar la existencia de una prohibición, sino, por el contrario, de determinar si existía una norma que permitía a Turquía ejercer su jurisdicción penal.

4 Corte Permanente de Justicia Internacional, "S.S. Lotus", (Francia/Turquía) Series A, na 10, 7 de septiembre de 1927 , p. 15.

5 Corte Permanente de Justicia Internacional, "S.S. Lotus", p. 18.

Corte Permanente de Justicia Internacional, "S.S. Lotus", p. 18.

Corte Permanente de Justicia Internacional, "S.S. Lotus", p. 18.

Corte Permanente de Justicia Internacional, "S.S. Lotus", pp. 18-19.

Corte Permanente de Justicia Internacional, "S.S. Lotus", pp. 20-21.

10 Corte Permanente de Justicia Internacional, “S.S. Lotus”, p. 21. 
El principio de prohibición y la clausura del derecho internacional como sistema normativo Natalia M. Luterstein

Esta decisión de la CPJI ha sido considerada como uno de los pilares sobre los cuales se sostiene el derecho internacional, al menos en su concepción clásica, que establece que se trata de un ordenamiento horizontal en donde todos los Estados son igualmente soberanos y que, por lo tanto, las normas jurídicas solo pueden surgir de su consentimiento. ${ }^{11}$ En este sentido, se ha afirmado que el derecho internacional es un derecho permisivo, porque la conducta de los Estados, en tanto entes de amplia capacidad, debe ser considerada como permitida salvo que esté prohibida. ${ }^{12}$

Asimismo, ha sido generalmente observado que la denominada postura "Lotus" implica adoptar una visión positivista del derecho internacional, construida sobre la base de la voluntad de los Estados como elemento central. ${ }^{13}$

En este punto, cabe señalar que el término "positivismo" tiene diferentes acepciones en la teoría general del derecho. Nino, por ejemplo, identifica cuatro posiciones. ${ }^{14}$ En primer lugar, menciona el denominado "escepticismo ético", que separa el derecho de la moral porque "no existen principios morales y de justicia universalmente válidos y cognoscibles por medios racionales y objetivos", ${ }^{15}$ pero concluye que, en realidad, esta posición no es esencial al positivismo. ${ }^{16}$ En segundo lugar, identifica el "positivismo ideológico", que sostendría que "cualquiera sea el contenido de las normas de derecho positivo, éste tiene validez o fuerza obligatoria y sus disposiciones deben ser necesariamente obedecidas por la población y aplicadas por los jueces, haciendo caso omiso de sus escrúpulos morales", aunque sea difícil encontrar algún jurista que adscriba plenamente a esta posición. ${ }^{17}$ En tercer lugar, el llamado "formalismo jurídico" establece que "el derecho está compuesto exclusiva o predominantemente por preceptos legislativos, o sea por normas promulgadas explícita y deliberadamente por órganos centralizados y no, por ejemplo, por normas consuetudinarias o jurisprudenciales" y, además, sostiene que el orden jurídico es siempre completo, consistente y preciso, es decir, autosuficiente. ${ }^{18}$ Finalmente, el "positivismo metodológico o conceptual", que sostiene que "el concepto de derecho no debe caracterizarse según propiedades valorativas sino tomando en cuenta solo propiedades descriptivas", es decir, "las proposiciones acerca de lo que el derecho dispone no implican juicios de valor y son verificables en relación a ciertos hechos observables

11 Buis describe el derecho internacional como un orden fundado en la parataxis, es decir, una estructura de coordinación entre Estados jurídicamente equiparados, cfr. E.J. Buis, "El derecho internacional público: concepto, características y evolución histórica”, en S. Gonzalez Napolitano (dir.), Lecciones de Derecho Internacional Público (Buenos Aires: Erreius, 2015), p. 2.

12 J. Klabbers, International Law (Cambridge: University Press, 2013), p. 22.

13 Ver, entre muchos otros, H.A. Steiner, "Fundamental Conceptions of International Law in the Jurisprudence of the Permanent Court of International Justice", en American Journal of International Law (1936) 30, p. 416; D. Kennedy, "International Law and the nineteenth Century: History of an Illusion", en Law Review Association of the Quinnipiac College School of Law (1997) 17, p. 118; J. Brunée, "Consent", en Max Planck Encyclopedia of Public International Law (Oxford: University Press, 2010); J. d'Aspremont y J. Kammerhofer, "Introduction: The future of International Legal Positivism”, en J. d'Aspremont y J. Kammerhofer (eds.), International Legal Positivism in a Post-Modern World (Cambridge: University Press, 2004), p. 3.

14 C. Nino, Introducción al Análisis del Derecho (Buenos Aires: Editorial Astrea, 1995[1973]), pp. 30-43.

15 Nino, Introducción al Análisis del Derecho, p. 30.

16 Nino, Introducción al Análisis del Derecho, p. 32.

17 Nino, Introducción al Análisis del Derecho, p. 32.

18 Nino, Introducción al Análisis del Derecho, p. 36.

Número de página no utilizable para citar 
empíricamente", posición que, según Nino, caracteriza al positivismo defendido por Bentham, Austin, Hart, Ross, Kelsen y Bobbio, entre otros. ${ }^{19}$

En el ámbito específico del derecho internacional también se ha señalado que el positivismo jurídico tiene varias acepciones. ${ }^{20}$ En general, sin embargo, se lo ha relacionado con el consensualismo que, a su vez, se vincula directamente con el principio de igualdad soberana de los Estados. ${ }^{21}$ Sin embargo, no todas las acepciones del positivismo en el derecho interno descriptas por Nino coinciden necesariamente con aquellas del derecho internacional. Podemos mencionar, en particular, aquella postura que Nino define como "formalismo jurídico", que sostiene que el derecho interno es aquel promulgado por los órganos legislativos centralizados ya que, como fuera señalado, el derecho internacional es un ordenamiento descentralizado que, además, considera como un modo válido de creación de normas a la costumbre internacional. ${ }^{22}$

Como consecuencia de sentencias como la de la CPJI en el caso "S.S. Lotus", se ha sostenido que el derecho internacional es un sistema positivista porque las normas son creadas por el consentimiento de los Estados - los propios sujetos del ordenamiento- y no surgen de ningún otro lado, como la religión o consideraciones de moralidad. ${ }^{23}$ Ello quiere decir que, desde una perspectiva genérica, para las posturas positivistas, las fuentes del derecho internacional deben estar basadas exclusivamente en el consentimiento de los Estados, lo que, a su vez, se desprende de la noción de la soberanía. ${ }^{24}$ En efecto, el llamado principio "Lotus" asume que la soberanía estatal es el punto de partida del derecho internacional de la misma forma en que la libertad individual es la base de los derechos internos. ${ }^{25}$

El principio identificado en "Lotus" ha sido aplicado por la sucesora de la CPJI, la Corte Internacional de Justicia (en adelante, “CIJ”) en diversos casos. Por ejemplo, en el asunto de las

19 Nino, Introducción al Análisis del Derecho, p. 37.

20 S. Besson, "Theorizing the sources of Internacional Law", en The Philosphy of International Law (Oxford: University Press, 2010), p. 165.

21 Besson, "Theorizing the sources of Internacional Law", p. 165.

22 Crawford señala que el consentimiento es expreso en el caso de los tratados y tácito en el caso de las normas consuetudinarias, cfr. J. Crawford, Chance, Order, Change: The course of International Law (La Haya: The Hague Academy of International Law, 2014), p. 64. Sin embargo, posturas críticas del derecho internacional, como las de David Kennedy y Martti Koskenniemi, sostienen que, en realidad, el derecho internacional es el resultado de un compromiso entre tradiciones iusnaturalistas y positivistas. En palabras de Koskenniemi, el derecho internacional es, a la vez, utópico y apologético, es decir, busca el bien común y, al mismo tiempo, responde a los intereses de los Estados, ver M. Koskenniemi, From apology to Utopia. The structure of international legal argument (Cambridge: University Press, 2005).

23 Koskenniemi, quien señala que la CPJI, al afirmar que el derecho internacional emana de los Estados, excluye la posibilidad de que surge de una moral pre-existente; asimismo señala que la CPJI también observó que las normas se crean con el objetivo de alcanzar metas comunes, vid. Koskenniemi, From apology to Utopia, p. 167; J. Klabbers, International Law, p. 24. Como se explicará al final del trabajo, aun a pesar de la vigencia del dictum del caso "S.S. Lotus", el consensualismo extremo del derecho internacional se ha ido erosionando para dar paso a una versión un poco más atenuada.

24 J. d'Aspremont, "Herbert Hart in today's international legal scholarship", en J. d'Aspremont, y J. Kammerhofer (eds.) International Legal Positivism in a Post-Modern World (Cambridge: University Press, 2014), pp. 144-145.

25 Koskenniemi, From apology to Utopia, p. 256. En el mismo sentido, con respecto al derecho en general, el positivisimo considera que las normas son aquellas creadas por el legislador humano -y no se trata de principios evidentes e inmutables del derecho natural-, cfr. C. Alchourrón. y E. Bulygin, Sistemas Normativos. Introducción a la metodología de las ciencias jurídicas (Buenos Aires: Astrea, 2012[1975]), p. 79, de la misma forma en que el positivismo en el derecho internacional entiende que las normas internacionales son creadas por el legislador Estado. 
El principio de prohibición y la clausura del derecho internacional como sistema normativo Natalia M. Luterstein

"Pesquerías Anglo-Noruegas", la CIJ no analizó si Noruega estaba autorizada a trazar la línea de base recta, sino si dicha forma de delimitar su territorio estaba prohibida o no por el derecho internacional. ${ }^{26}$ En la misma línea, en el llamado caso "Los Contras", la CIJ sostuvo que en derecho internacional no hay otras reglas diferentes de aquellas aceptadas por los Estados soberanos. $^{27}$

Finalmente, cabe mencionar que esta noción clásica de soberanía -en las que las obligaciones internacionales solo pueden emanar de la voluntad de los Estados- debe complementarse con lo dispuesto en otras decisiones seminales del derecho internacional en las que se sostuvo que dicha noción implica, en sí misma, ciertos deberes respecto de otros Estados soberanos. Así, por ejemplo, el laudo del asunto "la Isla de Palmas" afirmó que, si bien la soberanía en las relaciones inter-estaduales equivale a la independencia y a derechos exclusivos de los Estados soberanos sobre sus territorios, ella entraña, al mismo tiempo, el deber de proteger, dentro de tales territorios, los derechos de otros Estados, en particular, su derecho a la integridad y la inviolabilidad y de reclamar por sus nacionales en territorio extranjero. ${ }^{28}$ En el mismo sentido se expresaron el tribunal arbitral en el caso "Trial Smelter", sosteniendo que, según principios del derecho internacional, los Estados no tienen derecho a permitir que su territorio se use de manera de causar perjuicio por humo y vapores en o al territorio o propiedad de otro, ${ }^{29}$ y la CIJ, en el caso del "Canal de Corfú", donde afirmó que los Estados tienen la obligación de no permitir a sabiendas que su territorio sea usado para realizar actos contrarios a los derechos de otros Estados..$^{30}$

\section{Hans Kelsen y el derecho internacional}

La posición descripta en el punto anterior representaba el paradigma sobre el cual trabajó Hans Kelsen (1881-1973) cuando escribió Principles of International Law, en 1952, si bien en dicha obra no se refirió expresamente al caso "S.S. Lotus". Allí desarrolló la aplicación de su Teoría Pura

26 Corte Internacional de Justicia, Caso de las Pesquerias Anglo-Noruegas (Reino Unido c. Noruega), 18 de diciembre de 1951, p. 139.

27 Corte Internacional de Justicia, Caso de las Actividades Militares y Paramilitares en y contra Nicaragua (Nicaragua c. Estados Unidos de América), 27 de junio de 1986, párr. 269.

28 Laudo arbitral en el caso Isla de Palmas (Países Bajos c. EEUU), Decisión del 4 de abril de 1928, U.N.R.I.A.A., Volumen II, pp. 829-871.

29 Laudo arbitral en el caso Trial Smelter Case (EEUU, Canadá), Decisiones del 16 de abril de 1938 y 11 de marzo de 1941 , Volumen III, p. 1965.

30 Corte Internacional de Justicia, Caso del Canal de Corfú (Reino Unido c. Albania), 9 de abril de 1949, p. 22.

31 H. Kelsen, Principles of International Law (Nueva York: Rinchart \& Company, 1952), Traducción al español por Hugo Caminos y Ernesto Hermida (Buenos Aires: El Ateneo, 1965). En el presente trabajo se hará referencia a la traducción en español.

Número de página no utilizable para citar 
del Derecho al derecho internacional, considerada como una de las obras principales del positivismo. $^{32}$

Kelsen comienza por definir el derecho internacional como un conjunto de normas que regulan la conducta de los Estados en sus relaciones mutuas. ${ }^{33}$ Para determinar si el derecho internacional es verdadero derecho, este autor aplica las nociones desarrolladas en su Teoría Pura del Derecho y afirma que ello será así "si el acto coercitivo adoptado como reacción contra un acto ilícito puede ser interpretado como reacción de la comunidad jurídica internacional”. ${ }^{34}$ Kelsen observa que lo que muchos autores identifican como el problema del derecho internacional es que la comunidad jurídica internacional está completamente descentralizada, es decir, no tiene órganos especiales para la creación y aplicación del derecho, lo que le daría al derecho internacional calidad de un derecho primitivo. ${ }^{35}$ De todas maneras, Kelsen llega a la conclusión de que, a pesar de las diferencias con los derechos nacionales, el derecho internacional es derecho ya que se trata de "un orden coercitivo, un conjunto de normas que disponen sanciones socialmente organizadas para ser ejecutadas como reacción contra actos ilícitos". ${ }^{36}$ En virtud de sus características propias, las sanciones principales de este ordenamiento son las represalias y la guerra y prevalece la responsabilidad de tipo colectiva. ${ }^{37}$

Con respecto al modo de creación del derecho internacional, Kelsen señala que "la constitución de la comunidad internacional es el conjunto de normas (...) que regulan la creación del derecho internacional, o, en otros términos, que determinan las 'fuentes' del derecho internacional". ${ }^{38}$ Así, afirma que las dos fuentes del derecho internacional son la costumbre y los tratados. ${ }^{39}$

En este sentido, para identificar cuál es la norma fundamental de este ordenamiento, Kelsen asevera que el análisis debe partir de la norma de menor jerarquía, la que reconoce en una sentencia de un tribunal internacional. La validez de dicha sentencia la encuentra en el tratado que creó dicho tribunal y, por lo tanto, recurre a la expresión pacta sunt servanda como fundamento de validez de dicho tratado, expresión que caracteriza como una norma internacional general creada por la costumbre nacida de los actos de los Estados. En consecuencia, Kelsen establece

32 Si bien existen otros autores que representan el positivismo jurídico, Kelsen ha sido central para la formación jurídica de los juristas latinoamericanos y su Teoría Pura del Derecho es aún enseñada a los estudiantes en las universidades como una doctrina seminal. Para un análisis de la influencia del Kelsenismo en el estudio del Derecho, ver G. Lariguet, "Los muertos que vos matáis gozan de buena salud. Un análisis crítico del Kelsenismo", en Revista Latinoamericana de Filosofia Política (2015), Vol. IV, no 1, pp. 1-41.

33 Kelsen, Principios del Derecho Internacional, p. 3.

34 Kelsen, Principios del Derecho Internacional, p. 16

35 Kelsen, Principios del Derecho Internacional, p. 19. La discusión acerca de si el derecho internacional en realidad no es verdadero derecho se remonta a John Austin, quien sostuvo que el derecho internacional no era más que una moralidad positivizada que no cuenta con un soberano centralizado. Cf. Klabbers, International Law, p. 165.

36 Kelsen, Principios del Derecho Internacional, p. 343. Ver, en este punto, la crítica que realizan Alchourrón y Bulygin de la técnica de Kelsen de definir un sistema en función de sus normas, es decir, afirmar que un sistema será jurídico si está compuesto de normas jurídicas -es decir, de normas que prevén una sanción coercitiva-. Cfr. Alchourrón y Bulygin, Sistemas Normativos, pp. 94 y ss.

37 Kelsen, Principios del Derecho Internacional, p. 343.

38 Kelsen, Principios del Derecho Internacional, p. 259.

39 Kelsen, Principios del Derecho Internacional, p. 260. 
El principio de prohibición y la clausura del derecho internacional como sistema normativo Natalia M. Luterstein

que la norma básica debe ser una norma hipotética que admita la costumbre como hecho creador de normas y, por ende, la enuncia de la siguiente manera: "los Estados deberán comportarse como lo hayan hecho por costumbre". ${ }^{40}$ De esta forma, la costumbre internacional establecida por la norma hipotética fundamental estaba por encima del derecho convencional, al igual que el derecho constitucional en los ordenamientos internos. Según Kelsen, la norma consuetudinaria más importante era la regla del pacta sunt servanda. ${ }^{41}$

En este contexto, Kelsen sostuvo, siguiendo la línea de la CPJI en "S.S. Lotus", que cuando no existe una norma internacional aplicable a un caso concreto, es decir, si no está establecido en un tratado o en una norma consuetudinaria que un Estado tiene la obligación de comportarse de una manera determinada, éste es jurídicamente libre de conducirse como lo desee. ${ }^{42}$ En este sentido, Kelsen consideró aplicable el principio fundamental que establece que "aquello que no está jurídicamente prohibido a los sujetos del derecho, les está permitido" 43 y que, entonces, no podía afirmarse la existencia de lagunas porque "es lógicamente imposible que en un caso concreto no sea aplicable ni el derecho internacional convencional ni el consuetudinario". ${ }^{44}$ Por lo tanto, Kelsen sostuvo que cuando se afirma que existe una laguna jurídica, en realidad, se está diciendo que la solución es moral o políticamente no satisfactoria, ${ }^{45}$ pero no "una imposibilidad lógica de aplicación del derecho". "A6 Así, cuando se sostiene la existencia de una laguna, en realidad, "hay una divergencia entre el derecho positivo y otro 'derecho', considerado mejor o más justo". ${ }^{47}$

Al igual que la CPJI, Kelsen afirmó entonces que "si se le da la razón al actor [en nuestro ejemplo del caso "S.S. Lotus" sería Francia], se aplica la norma que impone una obligación al demandado [en nuestro ejemplo del caso "S.S. Lotus", sería Turquía]. Si rechaza la demanda, aplica la regla general según la cual todo lo que no está prohibido, está jurídicamente permitido". ${ }^{48}$ Concluye, de esta manera que "el derecho vigente es siempre aplicable y permite resolver cualquier litigio". 49

40 Kelsen, Principios del Derecho Internacional, pp. 357-358.

41 J. Von Bernstorff, The Public International Law Theory of Hans Kelsen. Believing in Universal Lawn (Cambridge: University Press, 2010), p. 166.

42 Kelsen, Principios del Derecho Internacional, p. 261.

43 Kelsen, Principios del Derecho Internacional, p. 262.

44 Kelsen hace referencia aquí a dos de las fuentes principales o modos válidos de creación del derecho internacional: los tratados y la costumbre, vid. Kelsen, Principios del Derecho Internacional, p. 261. Para más información sobre las fuentes de derecho internacional, ver, entre muchos otros, J. Barboza, Derecho Internacional Público (Buenos Aires: Zavalía, 2008 ); R. Moncayo, R. Vinuesa y H.D.T Gutiérrez Posse, Derecho Internacional Público (Buenos Aires: Zavalía, 1997), tomo I; J. Barberis, Formación del Derecho Internacional (Buenos Aires: Ábaco, 1994).

45 Kelsen, Principios del Derecho Internacional, p. 261.

46 Kelsen, Principios del Derecho Internacional, p. 328.

47 H. Kelsen, Teoría Pura del Derecho (traducción de Moisés Nilve) (Buenos Aires: Eudeba, 1994[1953]), p. 173.

48 Kelsen, Teoría Pura del Derecho, p. 172.

49 Kelsen, Teoría Pura del Derecho, p. 173. 


\section{El principio de prohibición y el postulado de la plenitud hermética del derecho}

En su obra Sistemas Normativos. Introducción a la metodología de las ciencias jurídicas ${ }^{50}$ (en adelante Sistemas Normativos) Alchourrón y Bulygin introducen la perspectiva de la lógica deóntica (es decir, aquella que se ocupa de los conceptos normativos - permisión, prohibición, obligación, etc. - y de los usos normativos del lenguaje) a los fines de analizar el funcionamiento del Derecho. Siguiendo ese marco teórico, definen sistema normativo como "un conjunto de enunciados que tiene (algunas) consecuencias normativas (para algún universo de casos y algún universo de soluciones)" ${ }^{51}$ y afirman que estos tienen las siguientes propiedades formales: a) completitud, b) independencia y c) coherencia. ${ }^{52}$ Los sistemas jurídicos son definidos como una subclase de los sistemas normativos: ${ }^{53}$ se trata de "sistemas normativos que contienen enunciados prescriptivos de sanciones, es decir, entre cuyas consecuencias hay normas o soluciones cuyo contenido es un acto coactivo". ${ }^{4}$

Dentro de la propiedad denominada completitud, estos autores se refieren al principio de prohibición -todo lo que no está prohibido, está permitido- para analizar la postura de aquellos autores, como Hans Kelsen, que consideran que todos los sistemas normativos son necesariamente cerrados. ${ }^{55}$

Sin embargo, Alchourrón y Bulygin critican esta posición examinándola desde una perspectiva lógica. En primer lugar, sostienen que los caracteres normativos "prohibido $p$ ", "no permitido $p$ " y "obligatorio no $p$ " son equivalentes. Por otro lado, explican que si se afirma que $p$ está prohibido en un sistema normativo $\alpha$, se está expresando una proposición normativa, que será verdadera si, y solo si, entre las consecuencias de dicho sistema normativo se halla una norma que prohíbe $p$-que puede estar enunciada como "prohibido $\not$ " o "no permitido $p$ ". En el mismo sentido, si se afirma que $p$ está permitido en un sistema normativo $\alpha$, la norma puede expresarse como "permitido $p$ " o "no prohibido $p " .{ }^{56}$ Agregan entonces que este tipo de permisiones y prohibiciones son "fuertes" si en un sistema normativo $\alpha$ se infiere que existe una norma que prohíbe $p$ en el caso $q$-existencia de una prohibición fuerte- y, por otro lado, existirá una permisión fuerte si de un sistema normativo $\alpha$ se infiere una norma que permite $p$ en un caso $q$. Estas prohibiciones o permisiones fuertes no son caracteres de la norma, sino de las conductas normadas por la norma, es decir, "son elementos de las proposiciones normativas en el mismo

\footnotetext{
Achourrón y Bulygin, Sistemas Normativos.

Achourrón y Bulygin, Sistemas Normativos, p. 6.

Achourrón y Bulygin, Sistemas Normativos, p. 91.

Achourrón y Bulygin, Sistemas Normativos, p. 94.

Achourrón y Bulygin, Sistemas Normativos, p. 98.

Achourrón y Bulygin, Sistemas Normativos, p. 170.

Alchourrón y Bulygin, Sistemas Normativos, p. 172.
} 
El principio de prohibición y la clausura del derecho internacional como sistema normativo Natalia M. Luterstein

sentido en que los caracteres normativos son elementos de las normas". Al mismo tiempo, "los caracteres de las conductas se definen en términos de los caracteres de las normas porque una conducta tiene carácter normativo cuando existe una norma que la permite o la prohíbe". ${ }^{57}$

Ahora bien, Alchourrón y Bulygin sostienen que suele afirmarse que una conducta está permitida por un sistema normativo por el solo hecho de que no está prohibida, supuesto que denominan una permisión débil, es decir, que "entre las consecuencias de un sistema normativo $\alpha$ no existe una norma que prohíba (o que no permita) $p$ en el caso $q$ ". Es decir, a diferencia de las permisiones fuertes, las permisiones débiles se refieren "a un hecho negativo, la inexistencia de una norma prohibitiva". ${ }^{58}$

A la luz de estas consideraciones lógicas, estos autores analizan las interpretaciones del principio de prohibición con relación a una versión fuerte y a una versión débil del término "permitido". 59 Con relación a la segunda, afirman que se trata de un "enunciado necesariamente verdadero, pues es analítico", lo que quiere decir que por definición, el enunciado es verdadero, como decir que todos los solteros no son casados. Explican que si de un sistema normativo $\alpha$ no se infiere una prohibición de $p$ en el caso $q$, entonces de dicho sistema no se infiere la prohibición de $p$ en el caso $q$-es decir que se configura una tautología-, ya que cuando de un sistema normativo $\alpha$ no se infiere una norma que prohíba $p$ en el caso de $q$, $p$ estaría permitido en sentido débil, que sería igual a "no prohibido" en el sentido fuerte..$^{00}$ Así, cuando respecto de un sistema $\alpha$ se afirma que $p$ está permitido, en el sentido de que existe una permisión débil, es porque no existe una prohibición en un sentido fuerte respecto de $p$.

Por otro lado, una interpretación en la versión fuerte implicaría afirmar que para todo sistema normativo $\alpha$, para toda conducta $p$ y para todo caso $q$, vale que si de un sistema normativo $\alpha$ no se infiere la prohibición de $p$ en el caso $q$, entonces de dicho sistema se infiere la permisión de $p$ en el caso $q .{ }^{61}$ En este caso, para que este principio sea verdadero, el sistema normativo debe ser cerrado, es decir, completo respecto de cualquier universo de $\operatorname{casos}^{62}$ y cualquier universo de soluciones, para lo que se necesitaría una regla de clausura que permita realizar dicha inferencia, cuestión que se desarrollará en la siguiente sección.

\footnotetext{
Alchourrón y Bulygin, Sistemas Normativos, p. 173.

Alchourrón y Bulygin, Sistemas Normativos, pp. 175-176.

9 Estos autores no analizan este principio desde la perspectiva del término "prohibición" porque consideran que una prohibición en el sentido débil, como la ausencia de una norma que permita $\mathrm{p}$ en un sistema normativo concreto, es muy poco usada. Cfr. Alchourrón y Bulygin, Sistemas Normativos, p. 176, nota a pie 12.

60 Alchourrón y Bulygin, Sistemas Normativos, p. 177.

61 Alchourrón y Bulygin, Sistemas Normativos, p. 178.

62 Alchourrón y Bulygin definen "universo de casos" como "el conjunto de todos los casos elementales (correspondientes a un universo de propiedades [es decir, conjunto de propiedades que pueden estar presentes o ausentes en los elementos de un universo de discurso, es decir el ámbito de lo normado, o sea, un conjunto de situaciones o estados de cosas-]), c $f r$. Alchourrón y Bulygin, Sistemas Normativos, p. 17. Más adelante profundizan sobre esta definición y explican que un conjunto de propiedades forman una división si son propiedades lógicamente disyuntivas, cada par de propiedades distintas es lógicamente excluyente y ninguna de las propiedades es lógicamente vacía, por lo que definen al universo de casos como "un conjunto de casos que forman una división". Cf. Alchourrón y Bulygin, Sistemas Normativos, p. 41.
} 
Alchourrón y Bulygin explican que, para algunos autores, todos los sistemas normativos son cerrados, es decir que son necesariamente completos con relación a cualquier universo de casos y cualquier universo de soluciones. ${ }^{63}$

Entre dichos autores, se encuentra, justamente, Hans Kelsen quien, como ya ha sido explicado con relación al derecho internacional en particular -como así también con relación al derecho en general-, sostenía que una conducta siempre tendrá una calificación normativa (su prohibición o la ausencia de prohibición, que implica su permisión). Si bien en una primera versión de su obra, Kelsen parecía sostener la existencia de un principio de prohibición en sentido fuerte, en una segunda versión modifica su interpretación de este principio para referirse a una versión débil del término "permitido". ${ }^{64}$ En este sentido, para poder seguir sosteniendo la inexistencia de lagunas (en palabras de Kelsen, la imposibilidad de aplicar el derecho vigente en un caso concreto porque ninguna norma jurídica indica la conducta debida), ${ }^{65}$ plantea que cuando un caso no está previsto en ninguna norma, se debe aplicar todo el ordenamiento jurídico, ya que este siempre es lógicamente aplicable. ${ }^{66}$

A la luz de este análisis, podría afirmarse que en el caso "S.S. Lotus", la CPJI aplicó una versión débil del principio de prohibición ya que no afirmó que en el derecho internacional existiera un sistema normativo $\alpha$ (por caso, los criterios de jurisdicción aplicables por los Estados) del cual se infiera una norma que permite $p$ (ejercer jurisdicción) en un caso $q$ (sobre un nacional de otro Estado por hechos cometidos en alta mar), sino que, por el contrario, afirmó un hecho negativo, es decir, que entre las consecuencias de un sistema normativo $\alpha$ no existía una norma que prohibiera (o que no permitiera) ejercer jurisdicción $(p)$ en el caso $q$, sobre nacionales de otro Estado por hechos cometidos en alta mar, entonces $p$, estaba permitido.

Ello quiere decir que pareciera que la supuesta inexistencia de lagunas planteada por Kelsen no da cuenta de un verdadero sistema completo o cerrado, sino que, en realidad, lo que se verifica es la inexistencia de prohibiciones débiles y que, en consecuencia, el derecho internacional público, aun examinado desde una perspectiva positivista, no sería un sistema realmente completo y cerrado.

63 Alchourrón y Bulygin, Sistemas Normativos, p. 184.

64 Para mayor detalle, vid. Alchourrón y Bulygin, Sistemas Normativos, pp. 185-186.

65 Kelsen, Teoría Pura del Derecho, p. 172.

66 Alchourrón y Bulygin, Sistemas Normativos, pp. 187-188. 


\section{La Corte Internacional de Justicia después de Lotus: dos Opiniones Consultivas}

El principio "Lotus" y la postura de Kelsen frente a las lagunas de derecho que, como fuera explicado supra, fue mantenida por la CIJ durante la jurisprudencia de sus primeros cuarenta años, parecen haber sido revisados en una decisión tomada en el marco de su competencia consultiva: ${ }^{67}$ la Opinión Consultiva del 8 de julio de 1996 sobre la Legalidad de la Amenaza o el Uso de Armas Nucleares. ${ }^{68}$ Como será explicado infra, de la lectura de esa Opinión podría concluirse que la postura claramente positivista sostenida por la CIJ se habría morigerado. Sin embargo, como también será desarrollado, con posterioridad a la Opinión Consultiva sobre las Armas Nucleares y a la controversia que causó el enfoque adoptado por la CIJ, el tribunal volvió a tener la oportunidad de analizar la legalidad de un acto en el derecho internacional y, nuevamente, el principio "Lotus" reapareció en escena.

\subsection{La Opinión Consultiva de la CIJ sobre la Legalidad de la Amenaza o Uso de Armas Nucleares}

A través de su Resolución 49/75, ${ }^{69}$ la Asamblea General de las Naciones le solicitó a la CIJ una Opinión Consultiva en la que le preguntó si la amenaza o uso de las armas nucleares están permitidos por el derecho internacional en alguna circunstancia. En su Opinión, la CIJ resolvió, inter alia: a) de forma unánime, que no existe una norma consuetudinaria ni convencional que autorice específicamente la amenaza o el uso de las armas nucleares $;^{70} \mathrm{~b}$ ) por once votos contra tres, que ni el derecho internacional consuetudinario ni el convencional prevén una prohibición comprensiva y universal de la amenaza o el uso de la fuerza como tal; ${ }^{71}$ y c) por siete votos contra siete - con voto de desempate del presidente-, que la amenaza o el uso de las armas nucleares sería contraria a las normas de derecho internacional aplicable en los conflictos armados, y en particular de los principios y reglas del derecho humanitario, pero que, en virtud del estado actual del derecho internacional, y de los elementos de hecho a su disposición, no podía concluir de forma definitiva si la amenaza o el uso de las armas nucleares sería legal o ilegal en una circunstancia extrema de legítima defensa, en la que la propia supervivencia del Estado estuviese en riesgo. ${ }^{72}$

67 Artículo 65 de la Carta de la Organización de las Naciones Unidas.

68 Corte Internacional de Justicia, Legalidad de la Amenaza o Uso de las Armas Nucleares, Opinión Consultva, 1.C.J. Reports 1996, p. 226, en adelante "OC sobre Armas Nucleares".

$69 \quad 15$ de diciembre de 1994.

70 Corte Internacional de Justicia, OC sobre Armas Nucleares, párr. 105(2)(A).

71 Corte Internacional de Justicia, OC sobre Armas Nucleares, párr. 105(2)(B).

72 Corte Internacional de Justicia, OC sobre Armas Nucleares, párr. 105(2)(E). 
Esto quiere decir que la CIJ decidió que el empleo de las armas nucleares "es difícilmente conciliable con el respeto de estas exigencias [los principios del derecho internacional humanitario]", y que debía hacerlo con reservas porque consideraba que no disponía de "suficientes elementos para poder concluir con certeza que el empleo de las armas nucleares estaría necesariamente en contradicción con los principios y las normas del derecho aplicable en los conflictos armados en todas las circunstancias".

Más allá de las críticas que la CIJ ha recibido con respecto al fondo de la decisión adoptada, ${ }^{73}$ también se han sugerido críticas a la forma en que la Asamblea General planteó la consulta. Al igual que en el caso de Francia en "S.S. Lotus", la Asamblea preguntó sobre la existencia de una permisión y no de una prohibición. Nuevamente, la CIJ decidió replantear la pregunta y afirmó como introducción al tema que, si bien no existía ninguna norma consuetudinaria ni convencional que autorizara la amenaza o el uso de las armas nucleares, en el derecho internacional la ilegalidad de ciertas armas no resulta de la ausencia de autorización, sino, por el contrario, se formula en terminos de prohibición. ${ }^{74}$

La conclusión final de la CIJ en el sentido de que del estado actual del derecho internacional y de los elementos de hecho a su disposición no podía concluir de forma definitiva si la amenaza o el uso de las armas nucleares sería legal o ilegal en una circunstancia extrema de legítima defensa en la que la propia supervivencia del Estado estuviese en riesgo, ha sido considerada por la doctrina como la determinación de un non liquet. ${ }^{75}$

Tanto en las presentaciones de los Estados ante la CIJ, como en el voto de la mayoría y en las opiniones concurrentes y disidentes, pueden encontrarse menciones a la doctrina "Lotus". Por ejemplo, el Reino Unido afirmó que era axiomático que, en ausencia de una regla prohibitiva oponible a algún Estado, la conducta de ese Estado debía ser permitida. ${ }^{76}$ En este sentido, varios jueces de la CIJ observaron que si se examinara la conclusión final a la luz del principio "Lotus", se podría inferir que lo que la CIJ afirmó es que existe una posibilidad de que el uso de armas nucleares pueda ser legal en ciertas circunstancias y que ello depende de la decisión de los Estados. ${ }^{77}$ En consecuencia, si se entendiese que la CIJ declaró un non liquet, se estaría afirmando que existe un vacío en la aplicación de los principios que se consideran correctos para regular la cuestión y en las circunstancias en las que puede considerarse que un Estado tiene el derecho de

73 T.L.H. McCormack, "A non liquet on nuclear weapons. The ICJ avoids the application of general principles of International Humanitarian Law", en International Review of the Red Cross (1997), Vol. 316, pp. 76-91; L. Condorelli, "Nuclear Weapons: a weighty matter for the International Court", en International Review of the Red Cross (1997), Vol. 316, pp. 9-20; E. David, “The Opinión of the International Court of Justice on the legality of the use of nuclear weapons", en International Review of the Red Cross (1997), Vol. 316, pp. 21-34.

74 Corte Internacional de Justicia, OC sobre Armas Nucleares, párr. 52.

75 Instituto que impide que una institución judicial emita un pronunciamiento sobre un punto de derecho porque concluye que el derecho no es claro. McCormack, "A non liquet on nuclear weapons"; P. Weil, "'The Court cannot conclude definitively..." Non liquet revisited" en Columbia Journal of Transnational Law (1997), 36, p. 117.

76 Citado en I. Dekker y W. Werner, "The completeness of International Law and Hamlet's Dilemma” en Nordic Journal of International Law (2000), 68, p. 241.

77 Corte Internacional de Justicia, OC sobre Armas Nucleares, Opinión Disidente del juez Shahabuddeeen, p. 376. 
actuar o no. Así, si se considerase que el derecho internacional nada tiene para decir sobre la legalidad de las armas nucleares, entonces, en aplicación del principio "Lotus", ante la ausencia de una regla prohibitiva, los Estados tendrían el derecho de usar esas armas. ${ }^{78}$

En este sentido, el presidente de la CIJ, el juez Bedjaoui, emitió una declaración adjunta a la Opinión Consultiva en la que buscó clarificar los alcances de la conclusión de la CIJ a la luz de la doctrina "Lotus". Allí señaló que la decisión de la CPJI en dicho caso debía ser entendida en su contexto particular ya que fue dictada en el "espíritu de su tiempo", cuando la sociedad internacional todavía contaba con pocas instituciones y estaba regulada por un derecho de estricta co-existencia, reflejo de la vigencia y fuerza del principio de soberanía del Estado. ${ }^{79}$ En esta línea, resaltó que en la actualidad, el derecho internacional es un derecho de cooperación que desarrolló fuertes organizaciones internacionales con su propia personalidad jurídica y en el que nociones como obligaciones erga omnes o reglas de ius cogens han modificado el enfoque positivista y voluntarista de principios del siglo XX. ${ }^{80}$ En consecuencia, señaló que, contrariamente a lo que la CPJI determinó en el caso "S.S. Lotus", la CIJ no concluyó que la amenaza o el uso de las armas nucleares fuera legal o ilegal, sino que, debido a ciertas incertidumbres de derecho y de hecho, no podía tomar una decisión, lo que de ninguna manera sugería que de ello se pudiera inferir una permisión. ${ }^{81}$

En su opinión disidente, el juez Shahabuddeen también señaló diferencias con respecto a los hechos en el caso "S.S. Lotus" y en la Opinión Consultiva, y afirmó que aun si se siguiera el principio "Lotus" y se afirmara que como no existe una prohibición en el derecho internacional de usar armas nucleares, entonces los Estados tienen el derecho de hacerlo, ese derecho residual no se debería extender a cuestiones que, por su propia naturaleza, podrían destruir la humanidad y la civilización y así, destruir las bases sobre las cuales existen los propios Estados. ${ }^{82}$ En ese sentido, afirmó que las nociones de independencia y soberanía sobre las cuales trabajó la CPJI en 1927 no incluían la posibilidad de que existieran Estados con la capacidad de destruir a toda la comunidad internacional. ${ }^{83}$

La jueza Higgins, por su parte, también en una opinión disidente, observó que la CIJ pronunció un non liquet sobre la base de incertidumbre respecto de cuestiones de hecho y de derecho, ${ }^{84}$ decisión que criticó señalando que, en realidad, el derecho internacional no contiene solamente prohibiciones totales ya que, por ejemplo, el derecho internacional humanitario [rama del

\footnotetext{
8 Corte Internacional de Justicia, OC sobre Armas Nucleares, Opinión Disidente del juez Shahabuddeeen, p. 389.

79 Corte Internacional de Justicia, OC sobre Armas Nucleares, Declaración del presidente Bedjaoui, párr. 12.

80 Corte Internacional de Justicia, OC sobre Armas Nucleares, Declaración del presidente Bedjaoui, párr. 13.

81 Corte Internacional de Justicia, OC sobre Armas Nucleares, Declaración del presidente Bedjaoui, párr. 14.

82 Corte Internacional de Justicia, OC sobre Armas Nucleares, Opinión Disidente del juez Shahabuddeeen, pp. 393-394.

83 Corte Internacional de Justicia, OC sobre Armas Nucleares, Opinión Disidente del juez Shahabuddeeen, p. 395.

84 Corte Internacional de Justicia, OC sobre Armas Nucleares, Opinión Disidente de la jueza Higgins, párr. 2.
} 
derecho internacional aplicable en conflictos armados] contiene principios enunciados de forma general que evitarían la declaración de non liquet. ${ }^{85}$

En esta Opinión Consultiva pareciera que la CIJ buscó la existencia de prohibiciones y permisiones fuertes para poder resolver la consulta y, cuando no logró encontrarlas, no pudo tomar una decisión definitiva en un sentido o en otro. Así debe leerse la declaración de su presidente, el juez Bedjaoui, en la que afirmó que, debido a ciertas incertidumbres de derecho y de hecho, el tribunal no había podido tomar una decisión. En efecto, en su voto, la mayoría de la CIJ sostuvo que no tenía suficientes elementos que le permitiesen concluir con certeza que el uso de armas nucleares estaría en desacuerdo con los principios y reglas del derecho aplicable a los conflictos armados en toda circunstancia. ${ }^{86}$ ¿Podrían esas incertidumbres ser consideradas como un ejemplo de lagunas de conocimiento, definidas por Alchourrón y Bulygin como los casos individuales en los que por falta de conocimiento de las propiedades de los hechos no se sabe si pertenecen o no a una clase determinada de casos (genéricos)? Si la respuesta fuera positiva, entonces no estaríamos hablando de una laguna lógica, sino de una laguna referida al nivel de aplicación de las normas a casos individuales, es decir, se trataría de un problema empírico-conceptual, lo que no excluiría la posibilidad de que el sistema fuese completo. ${ }^{87}$

\subsection{La Opinión Consultiva de la CIJ sobre la conformidad con el derecho internacional de la Declaración Unilateral de Independencia con respecto a Kosovo}

El 8 de octubre de 2008, la Asamblea General de las Naciones Unidas presentó ante la CIJ una solicitud de Opinión Consultiva en la que preguntaba si la declaración unilateral de independencia de las Instituciones Provisionales de Auto-Gobierno de Kosovo cumplía con el derecho internacional. ${ }^{88}$ En la Opinión Consultiva sobre la conformidad con el derecho internacional de la Declaración Unilateral de Independencia con respecto a Kosovo (en adelante, "Opinión Consultiva sobre la Declaración de Independencia de Kosovo"), la CIJ decidió, por diez votos contra cuatro, que dicha declaración de independencia no violaba el derecho internacional. ${ }^{89}$

En su decisión, la CIJ analizó nuevamente la consulta en términos de prohibiciones y determinó que la respuesta al interrogante presentado se refería a si el derecho internacional prohíbe o no la declaración de independencia. Si la CIJ concluía de forma positiva, entonces debía contestar que dicha declaración no se había hecho de conformidad con el derecho internacional. En consecuencia, debía determinar que la declaración había sido adoptada en violación del derecho

\footnotetext{
Corte Internacional de Justicia, OC sobre Armas Nucleares, Opinión Disidente de la jueza Higgins, párrs. 31-32.

Corte Internacional de Justicia, OC sobre Armas Nucleares, párr. 95.

Alchourrón y Bulygin, Sistemas Normativos, p. 50.

AG ONU Resolución 63/3.

89 Corte Internacional de Justicia, Opinión Consultiva sobre la Declaración de Independencia de Kosovo, 22 de julio de 2010 , I.C.J. Reports 2010, p. 403, párr. 123(3).
} 
internacional y no, por el contrario, que el derecho internacional le confería a Kosovo el derecho de declarar de forma unilateral su independencia o, a fortiori, le permitía separarse del Estado serbio. En este sentido, afirmó que era completamente posible que un acto, como la declaración unilateral de independencia, no fuera violatorio del derecho internacional, sin que ello constituyera el ejercicio de un derecho. ${ }^{90}$

Así, la CIJ, al determinar que la declaración unilateral de independencia no violaba el derecho internacional, adoptó nuevamente la postura "Lotus"; una vez que encontró que no existían prohibiciones, no necesitó identificar una permisión, ya que equiparó la frase "de conformidad con [el derecho internacional]" con "no viola [el derecho internacional]", lo que, nuevamente fue calificado como un enfoque altamente positivista. ${ }^{91}$

Si bien acordó con el fondo de la decisión, el juez Simma consideró en su declaración que este enfoque resultaba obsoleto para el derecho internacional contemporáneo. Asimismo, sostuvo que la CIJ no había contestado la consulta de forma satisfactoria, ya que ello hubiera requerido el análisis tanto de normas prohibitivas como de normas permisivas. Además, señaló que el principio "Lotus" entrañaba un anacronismo extremadamente consensualista que, de manera formalista, equipara la ausencia de prohibición con una norma permisiva. ${ }^{92} \mathrm{La}$ CIJ, al modificar el planteo de la pregunta (convertir "de acuerdo al derecho internacional" en "la existencia de una prohibición”), había limitado por demás su alcance. Agregó también que el hecho de que el orden jurídico internacional guarde silencio o neutralidad consciente respecto de un hecho o acto específico no tiene ninguna relación con un non liquet. En efecto, la neutralidad del derecho internacional sobre un punto puede solamente implicar que se trata de áreas que ese ordenamiento todavía no ha regulado, sin que ello entrañe un problema de coherencia. ${ }^{93}$

Surge entonces que en esta Opinión Consultiva, la CIJ parece retomar la línea de "Lotus" y, nuevamente, pensar el derecho internacional en términos positivistas como un ordenamiento supuestamente completo, al menos a través de la existencia de permisiones débiles.

90 Corte Internacional de Justicia, Opinión Consultiva sobre la Declaración de Independencia de Kosovo, párr. 56.

91 R. Wilde, "Accordance with International Law of the Unilateral Declaration of Independence in Respect of Kosovo", en American Journal of International Law (2011), 105, p. 303. Se ha observado que a través de este enfoque restrictivo, la CIJ evitó referirse a cuestiones más sensibles como la secesión, la auto-determinación y el reconocimiento. Cfr. R. Tricot y B. Sander, "Recent developments: the broader consequences of the International Court of Justice's Advisory Opinion on the unilateral declaration of independence in respect of Kosovo", en Columbia Journal of Transnational Law (2011) 49, p. 327.

92 Opinión Consultiva sobre la Declaración de Independencia de Kosovo, Declaración del juez Simma, párr. 3.

93 Opinión Consultiva sobre la Declaración de Independencia de Kosovo, Declaración del juez Simma, párr. 9. 


\section{La (pretendida) completitud del derecho internacional}

Alchourrón y Bulygin se refieren al concepto de completitud y afirman que un sistema normativo $\alpha$ es completo en relación con un universo de casos y un sistema de soluciones maximales determinados si y sólo si, $\alpha$ no tiene lagunas en dicho universo de casos con relación al universo de soluciones maximales, es decir, si $\alpha$ correlaciona un caso determinado con alguna solución maximal determinada. ${ }^{94}$

Estos autores señalan que una de las formas para conseguir que un sistema sea completo es a través de algún tipo de regla de clausura, o sea, "una regla que calificaría deónticamente todas aquellas acciones que no estuvieran calificadas ya por el sistema en cuestión”. Para ello, se debe clausurar el sistema, es decir, hacerlo completo con respecto a cualquier universo de casos y cualquier universo de acciones, preservando la coherencia del sistema. ${ }^{95}$ Sin embargo, Alchourrón y Bulygin señalan que "la clausura absoluta de un sistema normativo hipotético resulta (...) incompatible con la exigencia de que preserve ella la coherencia del sistema"; a lo sumo, se podrá lograr una clausura relativa a un universo de casos relevantes. Asimismo, señalan que la regla de clausura siempre debe ser permisiva, es decir que debe afirmar que toda acción no normada debe ser permitida. ${ }^{96}$

En el ámbito del derecho internacional, Hersch Lauterpacht (1897-1960), ex juez de la CIJ, sostenía que el derecho internacional era un orden jurídico completo y que, por lo tanto, era imposible que los tribunales internacionales pronunciaran un non liquet, ${ }^{97}$ ya que ambas cuestiones (la completitud y la prohibición de non liquet) eran dos caras de la misma moneda. ${ }^{98}$ Para sostener esta postura, los doctrinarios internacionalistas han recurrido a dos tipos de argumentos. El primero consiste en negar la posibilidad de existencia de lagunas -como lo ha hecho Kelsen-y el segundo, en aceptar dicha existencia pero afirmando que el propio ordenamiento internacional prevé el antídoto para llenarlas. ${ }^{99}$ De acuerdo con la segunda postura, serían los tribunales internacionales quienes deberían completarlas, evitando un non liquet. Sin embargo, conforme el

94 Alchourrón y Bulygin, Sistemas Normativos, p. 33. Los autores utilicen el término "soluciones maximales" para referirse a una solución que determina todos los contenidos que corresponden a un universo de acciones [conjunto finito de acciones básicas respecto de las cuales se analiza su estatus deóntico -permisión, prohibición u obligatoriedad], cfr. Alchourrón y Bulygin, Sistemas Normativos, pp. 15 y 19.

95 Alchourrón y Bulygin, Sistemas Normativos, p. 191.

96 Debido a que la propiedad formal coherencia no ha sido objeto de análisis en este trabajo, para mayores detalles me remito al desarrollo realizad por Alchourrón y Bulygin, Sistemas Normativos, p. 196.

97 P. Jessup, "The contribution of Sir Hersch Lauterpacht to the development of International Law, en 55(1) American Journal of International Law (1961), p. 98. Lauterpacht sostenía que un pronunciamiento de non liquet violaría la función del derecho internacional general de preservar la paz y de la función específica judicial de resolver las controversias por medios pacíficos. Cfr. Dekker y Werner, "The completeness of International Law", pp. 230-231.

98 M. Aznar-Gómez, “The 1996 Nuclear Weapons Advisory Opinion and non liquet in international law”, en International \& Comparative Law Quarterly (1999), 48(1), p. 4.

99 Aznar-Gómez, “The 1996 Nuclear Weapons Advisory Opinion”, p. 8. 
El principio de prohibición y la clausura del derecho internacional como sistema normativo Natalia M. Luterstein

derecho internacional clásico, los tribunales no pueden crear derecho, ya que ello es prerrogativa exclusiva de los Estados.

En este punto, cabe citar la declaración del juez Vereshchetin en la Opinión Consultiva sobre Armas Nucleares, quien afirmó que aquellos que proponen una prohibición de declarar un non liquet la consideran un corolario del carácter completo del derecho internacional y que aquellos que, por el contrario, no niegan la existencia de vacíos en el ordenamiento internacional, consideran que es obligación de la CIJ en un caso concreto llenar dichos vacíos haciendo referencia a principios generales de derecho o de la creación judicial para asegurar la completitud del derecho internacional. ${ }^{100}$ En la misma línea, se ha dicho que el derecho internacional podría auto-sanarse a través de su desarrollo normativo, lo que no equivale a la capacidad legisferante, sino que se refiere a la función judicial, que lo puede hacer a través de la aplicación de los principios generales de derecho y la equidad. ${ }^{101}$

En esta línea, una posición doctrinaria diferente sostiene que la existencia de una prohibición de declarar un non liquet no está adecuadamente justificada. En todo caso, la carga de llenar los vacíos no podría nunca recaer en el tribunal y, por lo tanto, un tribunal no puede ser responsabilizado por la indecisión o evasividad del derecho. ${ }^{102}$

Con relación al primer argumento -aquel el que sostiene la inexistencia de lagunas-, como fuera explicado supra, Alchourrón y Bulygin cuestionaron la imposibilidad de la existencia de lagunas a través de un análisis del principio de prohibición.

Con respecto al segundo argumento referido al rol de los tribunales frente a las lagunas normativas, estos autores han identificado tres casos en los que puede darse esta situación, específicamente cuando los jueces deben justificar una sentencia normativa, que es aquella que contiene normas que regulan lo que debe o puede hacerse en un caso en cuestión. ${ }^{103} \mathrm{El}$ tercer caso mencionado se refiere al supuesto en que del "sistema primario no se infiere que el demandado tenga la obligación de realizar el acto en cuestión, pero tampoco se infiere que le esté permitido abstenerse de realizarlo", es decir, "la conducta del demandado no está normativamente determinada". ${ }^{104}$ En ese caso, Alchourrón y Bulygin sostienen que el juez no tiene ninguna obligación específica, ni la de condenar ni la de rechazar la demanda, por lo que cumple su obligación genérica de juzgar tomando cualquiera de las dos decisiones. ${ }^{105}$ Ello así porque, en términos deónticos, esta situación equivale a "Obligatorio condenar $(p)$ o rechazar $(q)$ ", es decir $\mathrm{O}(p \vee q)$ que es compatible con $-\mathrm{O} p$ y $-\mathrm{O} q$. En la frase "si el juez no debe condenar, entonces debe rechazar la demanda", la expresión "no debe" no significa que ello está

\footnotetext{
100 Opinión Consultiva sobre sobre Armas Nucleares, Declaración del juez Vereshchetin, párr. 1

101 Weil, "The Court cannot conclude definitively...", p. 110. El autor se refiere a las fuentes del derecho internacional tal como están reflejadas en el artículo 38 del Estatuto de la Corte Internacional de Justicia.

102 Opinión Consultiva sobre sobre Armas Nucleares, Declaración del juez Vereshchetin, párr. 1.

103 Alchourrón y Bulygin, Sistemas Normativos, p. 210.

104 Alchourrón y Bulygin, Sistemas Normativos, pp. 219-220.

105 Alchourrón y Bulygin, Sistemas Normativos, p. 220.
} 
prohibido, sino que no tiene obligación de hacerlo. ${ }^{106}$ La única forma de superar esta laguna es modificar el sistema primario de normas, si está autorizado para ello. ${ }^{107}$ Si no se modifica dicho sistema para que incluya una norma que solucione el caso genérico, entonces ambas opciones están igual de (in)justificadas.

Como fuera señalado, en el derecho internacional clásico, es decir, en el derecho voluntarista de "Lotus" en el que los jueces no están autorizados a modificar el sistema primario de normas, la cuestión de la completitud se resolvía a través del principio de prohibición y la no aplicabilidad del non liquet. Esta fue también la postura adoptada en la Opinión Consultiva sobre la Declaración de Independencia de Kosovo. Ello implica que la completitud del sistema no solo existiría de facto, sino también de iure. ${ }^{108}$

En este punto, cabe referirse nuevamente a Alchourrón y Bulygin, quienes sostienen que el postulado de la plenitud hermética, es decir de que los sistemas jurídicos son necesariamente cerrados no tiene justificación, sino que es un ideal puramente racional. ${ }^{109}$ Solamente en ciertos casos excepcionales como el derecho penal liberal que contiene la regla de clausura nullum crimen este postulado es verdadero. ${ }^{110}$

Cabe aclarar aquí, finalmente, que la teoría los sistemas normativos de estos autores puede identificarse con cualquier conjunto de normas, sin importar su cantidad mientras que, normalmente, el análisis doctrinario que se ha hecho con referencia al derecho internacional, ha sido desde una perspectiva general, abarcativa de todo el ordenamiento.

\section{A modo de conclusión}

En este trabajo se estudiaron sistemas normativos puntuales en los que se examinó la aplicabilidad del principio de prohibición. De los argumentos presentados en el asunto "S.S. Lotus", surgía la posibilidad de analizar si existían lagunas respecto de la cuestión del ejercicio de la jurisdicción estatal. La CPJI, al afirmar que el ordenamiento internacional no prohibía el ejercicio de la jurisdicción sobre nacionales de otro Estado por hechos cometidos en alta mar, concluyó que ello implicaba la existencia de una permisión. De la misma manera, en la Opinión Consultiva sobre la Declaración de Independencia de Kosovo, la CIJ sostuvo que al no existir una prohibición respecto de ese tipo de declaraciones, se podía afirmar que estaban permitidas

106 Alchourrón y Bulygin, Sistemas Normativos, p. 221.

107 Alchourrón y Bulygin, Sistemas Normativos, p. 222.

108 Weil, "The Court cannot conclude definitively...", p. 112.

109 Alchourrón y Bulygin, Sistemas Normativos, pp. 233-234.

110 Alchourrón y Bulygin, Sistemas Normativos, p. 246. Si bien excede los límites de este trabajo, cabría hacer un análisis diferenciado respecto del derecho internacional penal. 
por el derecho internacional. Como ya ha sido explicado supra, estas dos decisiones han sido consideradas como ejemplos de sistemas normativos completos.

Sin embargo, en ambos casos, la permisión identificada por los tribunales no era un hecho positivo, sino que era una permisión en el sentido débil, es decir, aquella que se infiere de afirmar que no existe una prohibición en sentido fuerte, lo que implica que, en realidad, el sistema $\alpha$ no correlaciona un caso determinado con ninguna solución, por lo que la existencia de lagunas sería compatible con la existencia de permisiones débiles. En palabras de Alchourrón y Bulygin, "la versión débil del principio no clausura el sistema y es perfectamente compatible con la existencia de lagunas". ${ }^{111}$ En consecuencia, al contrario de lo sostenido por varios doctrinarios citados, el principio de prohibición desarrollado en "S.S. Lotus" no sirve para clausurar el sistema y afirmar que no existen lagunas.

Por otro lado, en la Opinión Consultiva sobre las Armas Nucleares la CIJ no pudo aplicar nuevamente este razonamiento porque en este caso no logró concluir de forma definitiva la inexistencia de una prohibición fuerte respecto del uso de armas nucleares, lo que, en consecuencia, le impidió inferir la existencia de una permisión débil. Desde otra perspectiva, como fue explicado supra, se puede interpretar la conclusión de la CIJ en el sentido de que identificó una laguna de conocimiento al determinar que existía incertidumbre respecto del derecho y de los hechos, por lo que tampoco se podría sostener que ello entraña la completitud del derecho internacional con relación a la amenaza o al uso de estas armas.

En esta línea, surge de este trabajo que, contrario a lo afirmado por Kelsen, las normas del derecho internacional no pueden ser consideradas como un sistema completo.

Finalmente, a ello cabe agregar que, en el derecho internacional contemporáneo ya no es solamente la voluntad de los Estados la que determina su ámbito material. El proceso de creación de nuevas normas es complejo y descentralizado y existe un gran número de cuestiones que no están aún reguladas. ${ }^{112}$ Asimismo, existen otros actores no estatales como las organizaciones internacionales que tiene una incidencia en la creación de normas internaciones y, como ya fuera señalado, nociones tales como las obligaciones erga omnes o reglas de ius cogens han modificado el enfoque positivista y puramente voluntarista de principios del siglo XX. En efecto, los cambios del derecho internacional identificados supra, la Organización de las Naciones y el Consejo de Seguridad, la aparición en la escena internacional de los individuos y el consecuente desarrollo de ramas como el derecho internacional de los derechos humanos y el derecho internacional penal han transformado el ordenamiento internacional de los tiempos del S.S. Lotus. Incluso, la propia CIJ que, mayormente ha adoptado dicha postura, ha utilizado, al mismo tiempo, argumentos que claramente se refieren a otro tipo de criterios, diferentes de aquellos que se derivan de la voluntad de los Estados, como por ejemplo, a "consideraciones elementales de

111 Alchourrón y Bulygin, Sistemas Normativos, p. 177.

112 Weil, “The Court cannot conclude definitively...", p. 118. 
humanidad"113, a "un propósito voluntario y humanizador", 114 y a obligaciones erga omnes que competen a todos los Estados, como la prohibición de esclavitud, del apartheid o del genocidio. ${ }^{115}$ El consentimiento del Estado como requisito sine qua non para la creación de normas internacionales ha perdido su rol exclusivo, permitiendo la aparición de un nuevo derecho internacional que a veces -aunque no del todo- parece alejarse del positivismo de la CPJI en el caso "Lotus".

Ello permite concluir que, sostenido en una tensión todavía no resuelta, el derecho internacional deja entrever las dificultades que a fines del siglo XX y principios del siglo XXI representa el concepto de soberanía y sus límites.

113 Corte International de Justicia, Caso del "Canal de Corfú" (Reino Unido de Gran Bretaña e Irlanda del Norte Corte International de Justicia, c. Albania) 9 de abril de 1948, I.C.J Reports 1949, p. 22.

114 Corte International de Justicia, Opinión Consultiva sobre las "Reservas a la Convención para la Prevención y Sanción del delito de Genocidio", 28 de mayo de 1951, I.C. J. Reports 1951, p. 23.

115 Corte International de Justicia, Caso "Barcelona Traction Light and Power Company Limited" (Bélgica c. España), 5 de febrero de 1970, I.C.J Reports 1970, párrs. 33-34.

Número de página no utilizable para citar 